\title{
Effect of Allium sativum (Garlic) Extract on Blood Coagulation and Fibrinolysis
}

\author{
Rama Narsimha Reddy A*, Srividya L, Swamy TP and Prasad VB \\ Jyothishmathi Institute of Pharmaceutical Sciences, Karimnagar, Telangana State, \\ India
}

\section{Research Article \\ Volume 2 Issue 1}

Received Date: November 27, 2017

Published Date: December 07, 2017

*Corresponding author: Rama Narsimha Reddy A, Jyothishmathi Institute of Pharmaceutical Sciences, Karimnagar, Telangana State, India, Tel: 09908457927; E-mail: anreddyram@gmail.com

\section{Abstract}

The present study was aimed to evaluate the effect of Allium sativum (Garlic) extract on coagulation of blood and fibrinolysis of blood clot. Capillary tube method was used to estimate the clotting time of blood. 20 healthy human volunteers were included in this study and acted as self control. The variation in the clotting time of blood in presence of various doses of garlic extract was estimated. The results of the present study showed that anticoagulant property of the extract. It was also found the fibrinolytic activity of the extract may be by preventing or prolonging the time required for clot formation by altering the coagulation mechanism.

Keywords: Allium sativum; Garlic; Anticoagulant property; Fibrinolysis; Coagulation; Blood clot

\section{Introduction}

Garlic (Allium sativum) is a popular vegetable with a variety of medicinal properties. Garlic bulbs are edible, inexpensive and are readily available. These are used as traditional dietary and medicinal purposes like antiinfective agents. The Garlic Porridge is a kind of herbal diet which lowering blood pressure and blood lipid, soften blood vessel. The tonic diet is given for nourishing and moistening the lung, nourish blood soothing the liver and lower the blood pressure. Garlic also found to be used as antiprotozoal activity against Entameoba histolytica, candidiasis. Cloves are known to possess antimicrobial, anticancer, antioxidant, antidiabetic, antiemetic, antihypertensive, hypoglycemic, hypolipidemic, and immunomodulatory [1-3]. Garlic consumption is an alternative thrombolysis medicine, which has been used for many years in different cultures [4]. Allicin, one of the garlic components, could have therapeutic effects, including anti-microbial effect, immunostimulating properties, improve fibrinolytic activity, inhibit platlet aggregation and adhesion and also reduce blood pressure [4].

Fibrin is an insoluble protein that can be dissolved by the proteolytic enzymes, plasmin which could be activated by circulating plasma precursor plasminogen, which is activated by tissue-type plasminogen activator (tPA) [5,6]. Regulation of the fibrinolytic enzyme system is due to activity of Plasminogen activator inhibitor- 1 (PAI-1) and plasminogen activator inhibitor-2 (PAI-2). Unwanted accumulation of fibrin in the arterial can decrease fluidity of blood circulation and cause cardiovascular diseases (CVD) such as myocardial infarction and stroke [7]. Current medication such as coumarin and warfarin are the cost-effective fibrinolysis treatment [8]. Urokinase which was derived from human urine has been broadly employed for thrombolytic therapy, but it has low specificity to fibrin and high cost [8]. The present study aimed to investigate the effect of 


\section{Advances in Pharmacology and Clinical Trials}

garlic extract on coagulation of blood using in vitro models.

\section{Materials and Methods}

\section{Preparation of Extract}

Fresh Allium sativum cloves (garlic bulbs) were procured from local market and the outer skin of the garlic cloves was peeled and crushed in a garlic press. The paste of the garlic cloves were done by using mixer. The mass or paste of the garlic was pressed manually to get an oil or extract and was collected in a container and obtained crude extract was used directly for the evaluation.

\section{Effect of Garlic Extract on Coagulation of Blood}

A total of 20 adult healthy volunteers (with average age of $18 \pm 1$ years) were taken for the study. After taking consent from the subjects, the clotting time (CT) was estimated using the capillary tube method [9]. In the second setup, different volumes of crude extract of garlic $(0.1,0.2,0.3 \mathrm{ml})$ and blood sample $(1 \mathrm{ml})$ was mixed and was used for the evaluation of clotting time using same subject and noted the CT time.

\section{Effect of Garlic Extract on Fibrinolysis of Clotted Blood}

To evaluate the effect of garlic extract on Fibrinolysis, the above mentioned same subjects were used. Blood samples were collected in a container without addition of any anticoagulants. After formation of fibrin clot, the garlic extract was added to the clot at different volumes and noted for the observations with proper mixing.

\section{Statistical Analysis}

All the results of the study were expressed as mean \pm SD. Paired $t$ test was used to compare results. $\mathrm{P}<0.05$ is considered as statistical significance in the present study.

\section{Results and Discussion}

The volume of extract obtained with 100grams of Allium sativum is $8.5 \mathrm{ml}$.The extract was found to be as viscous, yellow in color. The effect of garlic extract on coagulation of blood and Fibrinolysis of blood clot was showed in Table 1 . The results of the study clearly showed the increase in the clotting time of blood and were found as dose dependent. Mixture of equimolar volumes of blood and extract causes the blood remains maintains as it fluid property without any clot formation.
The formed clot was found to be partially dissolved with addition of garlic oil and was found to be volume dependent.

\begin{tabular}{|c|c|c|}
\hline S.No & $\begin{array}{c}\text { Volume of garlic extract } \\
\text { (ml) }\end{array}$ & $\begin{array}{c}\text { Clotting time in } \\
\text { minutes }\end{array}$ \\
\hline 1 & 0 (Control) & $4.5 \pm 0.52$ \\
\hline 2 & 0.1 & $7.7 \pm 0.65^{*}$ \\
\hline 3 & 0.2 & $10.4 \pm 0.70^{*}$ \\
\hline 4 & 0.3 & $18.8 \pm 1.34^{* *}$ \\
\hline
\end{tabular}

Table 1: Effect of garlic extract on coagulation of blood Data was expressed as mean \pm SD $(n=20),{ }^{*} \mathrm{p}<0.05$, ${ }^{* *} \mathrm{p}<0.01,{ }^{* * *} \mathrm{p}<0.001$ vs control

Blood coagulation or clot formation had been takes place in different stages i.e. platelet plug formation and formation of clot. The results showing the increased CT indicates the prevention of platelet/clotting factor activation. The fibrinolytic enzyme prevents formation of fibrin clots in circulatory system [9]. Some medicines like urokinase and streptokinase are widely used to inhibit homeostatic disorders, particularly thromboemboli [10]. Fibrinolytic effects of garlic have been extensively studied in vivo. One Indian study showed that intake of garlic in a regular diet could remove fibrin clots and reduce the incidence of CVD [11]. Almost all human researches on fibrinolytic activity of garlic have been found to have positive effect in fibrinolysis [12-14]. Another study showed antiplatelet garlic activity and inhibiting platelet thromboxane formation [15]. The essential oils in garlic and onion act by interfering with thromboxane synthesis [16]. It has been shown that a minor component (4-10\%) of natural' garlic oil is responsible for inhibition of platelet aggregation which provides for anticoagulant activity [17].

\section{Conclusion}

The results of the present study suggest the anticoagulant property of garlic extract by preventing or prolonging the time required for clot formation by altering the coagulation mechanism. It was also found the fibrinolytic activity with garlic extract.

\section{Acknowledgements}

All the authors are thankful to the management of the Jyothishmathi Institute of Pharmaceutical Sciences, Karimnagar, Telangana State and the volunteers for their support to carry out the research work. 


\section{Advances in Pharmacology and Clinical Trials}

\section{References}

1. Pakdel F, Ghasemi S (2017) Antibacterial Effects of Garlic Extracts and Ziziphora Essential Oil on Bacteria Associated with Peri-Implantitis. J Clin Diagn Res 11(4): ZC16-ZC19.

2. Katey M, Ourania P, Miguel A, Sonia C, Carsten T, et al. (2005) Allyl alcohol and garlic (Allium sativum) extract produce oxidative stress in Candida albicans. Microbiology 151(10): 3257-3265.

3. Otunola GA, Afolayan AJ (2017) Characterization, antibacterial and antioxidant properties of silver nanoparticles synthesized from aqueous extracts of Allium sativum, Zingiber officinale, and Capsicum frutescens. Pharmacogn Mag 13(2): 201-208.

4. García Gómez LJ, Sánchez-Muniz FJ (2000) Review: cardiovascular effect of garlic (Allium sativum). Arch Latinoam Nutr 50(3): 219-229.

5. Ko JA, Koo SY, Park HJ (2008) Effects of alginate microencapsulation on the fibrinolytic activity of fermented soybean paste (Cheonggukjang) extract. Food Chemistry 111(4): 921-924.

6. Wiman B (2000) The fibrinolytic enzyme system. Basic principles and links to venous and arterial thrombosis. Hematol Oncol Clin North Am 14(2): 325-338.

7. Carr ME Jr, Dent RM, Carr SL (1996) Abnormal fibrin structure and inhibition offibrinolysis in patients with multiple myeloma. J Lab Clin Med 128(1): 83-88.

8. Electricwala A, Sawyer RT, Jones CP, Atkinson T (1991) Isolation of thrombin inhibitor from the leech Hirudinaria manillensis. Blood Coagul Fibrinolysis 2(1): 83-89.

9. Reddy ARN, Srividya L. Manual of practical Anatomy and Physiology, Sara book publication, Gujarat, Pp: 50-55.
10. Wiman B (2000) The Fibrinolytic enzyme system: Basic Principles and Links to Venous and Arterial Thrombosis. Hematology/Oncology Clinics 14(2): 325-338.

11. Bordia A, Verma SK, Srivastava KC (1998) Effect of garlic (Allium sativum) on blood lipids, blood sugar, fibrinogen and fibrinolytic activity in patients with coronary artery disease. Prostaglandins Leukot Essent Fatty Acids 58(4): 257-263.

12. Gadkari JV, Joshi VD (1991) Effect of ingestion of raw garlic on serum cholesterol level, clotting time and fibrinolytic activity in normal subjects. J Postgrad Med 37(3): 128-131.

13. Kiesewetter H, Jung F, Mrowietz C, Pindur G, Heiden M, et al. (1990) Effects of garlic on blood fluidity and fibrinolytic activity: a randomised, placebocontrolled, double-blind study. Br J Clin Pract Suppl 69: 24-29.

14. Jain RC (1977) Effect of garlic on serum lipids, coagulability and fibrinolytic activity of blood. Am J Clin Nutr 30(9): 1380-1381.

15. Bordia A, Bansal HC, Arora SK, Rathore AS, Ranawat $\mathrm{RV}$, et al. (1974) Effect of the essential oil (active principal) of garlic on serum cholesterol, plasma fibrinogen, whole blood coagulation time and fibrinolytic activity in alimentary lipaemia. J Assoc Physicians India 22(3): 267-270.

16. Makhija ANJY, Vanderhock, Bailey JM (1979) Inhibition of platelet aggregation and thromboxane synthesis by onion and garlic. Lencet 1(8119): 781.

17. Ariga TS, Oshiba S, Tamada T (1980) Platelet aggregation inhibitor in garlic. Lancet 1(8212): 150151. 